\title{
Discrimination-reversal skills of primates: The reversal/acquisition ratio as a function of phyletic standing ${ }^{1,2}$
}

DUANE M. RUMBaUgh AND MARY BELLE POURNELLE

SAN DIEGO STATE COLLEGE AND INSTITUTE FOR COMPARATIVE BIOLOGY

The ratio of reversal performance to acquisition performance in discrimination reversal learning differentiated primate groups and varied with acquisition proficiency.

There is general agreement that the capacity to execute efficient reversals of previously mastered discriminations has increased with the evolution of animal life and that in some manner this capacity contributes to the extraordinary concept formation skills characteristic of primates (Harlow, 1958). That discriminationreversal skills might be particularly sensitive to the species variable (Harlow \& Hicks, 1957), basically involved in those mediational processes which both anticipate and involve language (Kendler \& Kendler, 1964), and a contributor to the varied effects of overtraining upon performances which apparently interact with both the species and task variables (Warren, 1962; Reese, 1963; Sperling, 1965) makes the understanding of reversal processes particularly important.

\section{Method}

Data of certain discrimination reversal (DR) experiments, all conducted locally, were analyzed to compare acquisition (A) and reversal (R) performances for a group of squirrel monkeys with another group comprised of apes and macaques.

All Ss had served previously in learning-set studies which entailed approximately 2,000 to 3,000 trials of either 6 -trial and/or criterional object-quality discrimination problems. The DR data for 7 squirrel monkey Ss (Saimiri sciureus) were from the 50 problems of Phase III of the Rumbaugh \& Ensminger (1964) study; DR data for a group of 16 ape (6 Pan, 6 Gorilla, 3 Pongo, 1 Hylobates) and 5 macaque monkey Ss were from the Rumbaugh \& McCormack study program (1965, also Rumbaugh \& Rice, 1962). In the latter study measures were from the last 11 problems of $D R$ training, those problems being the ones within which Ss achieved an interproblem criterion (10 correct trial 2, reversal). Of 23 Ss given this training, the 21 that met that criterion were selected for purposes of comparisons drawn in this paper.

All measures were taken in WGTA test situations and from experimental phases in which, on a random basis among problems, either 7, 9 , or 11 acquisition trials preceded 8 reversal trials. All Ss were food deprived and received a variety of rewards from foodwells bared by a pushing response directed toward the object chosen on a given trial. Noncorrection training methods were used in all instances.

\section{Resulis and Discussion}

Each squirrel monkey $\mathrm{S}$ was matched either with an ape or macaque $S$ on the basis of performance on $A$ trials. The 6 ape and 1 macaque Ss selected by this matching procedure held quite constant from $A$ to $R$ (Table 1), but their squirrel monkey counterparts dropped from $A$ to $R$ an average of $8.50 \%(t=4.34$, $\mathrm{df}=12, \mathrm{p}<.01)$.

There is good reason to believe that these particular squirrel monkeys were superior in their DR skills, for
Table 1. The Acquisition and Reversal Performances of Seven Squirrel Monkeys and Their Ape or Macaque Members Matched for Acquisition Level

\begin{tabular}{|c|c|c|c|c|}
\hline \multicolumn{3}{|c|}{$\begin{array}{l}\text { Acquisition } \\
\text { (trial } 1_{A} \text { excluded) }\end{array}$} & \multicolumn{2}{|c|}{$\begin{array}{c}\text { Reversal } \\
\text { (trial } l_{R} \text { excluded) }\end{array}$} \\
\hline $\begin{array}{c}\text { Squirrel Ss } \\
88.75 \%+ \\
88.23 \\
84.23 \\
32.50 \\
32.48 \\
82.48 \\
81.70\end{array}$ & $\begin{array}{l}\text { Matched Ss } \\
89.00 \mathrm{C}-3^{*} \\
88.40 \mathrm{C}-2 \\
85.20 \mathrm{O}-3 \\
83.70 \mathrm{M}-11 \\
83.70 \mathrm{G}-11 \\
82.60 \mathrm{C}-4 \\
80.20 \mathrm{G}-1\end{array}$ & $\begin{array}{c}\text { (years age) } \\
2.8 \\
3.3 \\
4.4 \\
17.0 \\
6.6 \\
3.1 \\
2.6\end{array}$ & $\begin{array}{c}\text { Squirrel Ss } \\
79.72 \\
76.57 \\
80.29 \\
80.57 \\
71.43 \\
71.43 \\
70.86\end{array}$ & $\begin{array}{c}\text { Matched Ss } \\
91.40 \\
87.00 \\
83.10 \\
88.30 \\
90.90 \\
77.90 \\
80.50\end{array}$ \\
\hline$=84.34 \%$ & $84.69 \%$ & & $75.34 \%$ & $85.59 \%$ \\
\hline
\end{tabular}

${ }^{*} \mathrm{C}=$ Chimpanzee, $G=$ gorilla, $M=$ macaque, and $O=$ orangutan

they had been selected for use as Ss in the Rumbaugh and Ensminger study by reason of their relatively highorder learning set performance in earlier experiments. Assessment of the DR proficiency of the ape/macaque Ss of Table 1 revealed that as a group they were slightly above average, as $\overline{\mathrm{X}}_{\mathrm{A}}=78.60 \%$ and $\overline{\mathrm{X}}_{\mathrm{R}}=83.80 \%$ for the entire group $(N=21)$ from which they were drawn. For the best $7 \mathrm{Ss}$ of the ape/macaque group, $\overline{\mathrm{X}}_{\mathrm{A}}=\mathbf{9 1 . 4 3 \%}$ and $\overline{\mathrm{X}}_{\mathrm{R}}=88.37 \%$; for the worst $7 \mathrm{Ss}$ of that group, $\overline{\mathrm{X}}_{\mathrm{A}}=73.24 \%$ and $\bar{X}_{R}=78.27 \%$. Whereas the best 7 Ss dropped in percentage correct from $A$ to $R$ and the worst 7 Ss gained from $A$ to $R$, those $7 \mathrm{Ss}$ selected (Table 1) held quite constant. A split of the original $\mathrm{N}=23$ (includes 2 Ss that did not meet the interproblem criterion for DR) at their median A similarly revealed that of the Ss above the median, 9 dropped from $A$ to $\mathrm{R}$ and of those below the median 9 gained (median sign test $p<.01$ ).

As matching on A had not yielded comparable $R$ values, it was considered that possibly matching on $R$ might yield comparable A values. Matching procedures yielded an ape/macaque group with an $R=77.16 \%$, a value which corresponds closely with the squirrel monkeys' $R$ value of $75.84 \%$. The A values associated with the $R$ matched members differed markedly, however, $A=84.34 \%$ for the squirrel monkey $S s$ and $A=73.06 \%$ for the ape/macaque Ss $(t=3.02$, df $=12, p<.05)$.

That neither of the matching procedures resulted in two groups with comparable A-R skills carries the implication that the $\mathrm{R} / \mathrm{A}$ functional relationship varies among primate groups, most probably according to fundamental differences in how they go about learning discrimination problems. Equivalent $A$ levels for differ- 
ent primate groups does not imply equivalent $R$ levels, and vice versa. Alternatives, such as the one of transfer suppression (Riopelle, 1953) operating differentially among taxa, will have to be explored (e.g., Warren \& Kimball, 1959).

Figure 1 portrays $\mathrm{R} / \mathrm{A}$ functions, in reference to $\mathrm{A}$ levels, as we believe them to be on the basis of the foregoing analyses. In addition to those 7 squirrel monkeys of Table 1, 4 other squirrel monkeys, whose points are below $A=80 \%$, are included. Their training consisted of 1,800 trials of DR training given in accord with the previously described methods, but this was their very first training in a formal training situation, i.e., they had no prior learning set training. Their $\mathrm{R} / \mathrm{A}$ ratios and $\mathrm{A}$ values were calculated for the last 25 problems of that training. Since the other 7 squirrel monkey Ss, superior for their kind, all dropped from $A$ to $R$, less superior Ss should have lower A levels and lower $R / A$ ratios. But since totally naive Ss should be initially $50 \%$ correct on both $A$ and $R$, the $R / A$ ratio must begin at 1.00 .

All members of the ape/macaque pool $(\mathrm{N}=21)$ are included in Fig. 1. The solid-line portion of their function is reasonably well buttressed by Ss' values. Note that it drops below $\mathbf{R} / \mathrm{A}=1.00$ where $\mathrm{A}$ values are high in accord with the finding that ape/macaque Ss above the median $\mathrm{A}$

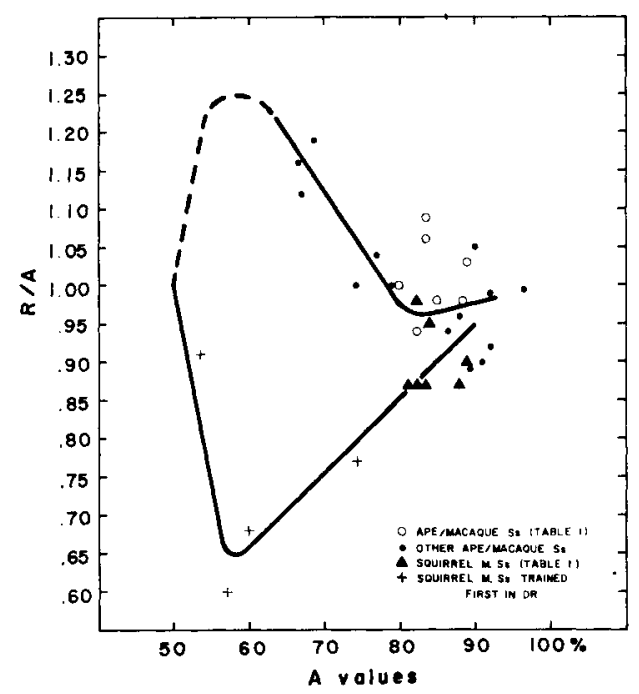

Fig. 1. The $R / A$ ratio values $(\%+$ on reversal $/ \%+$ on acquisition) plotted as a function of $A$ values ( $\%+$ on acquisition) for groups of $\mathrm{Ss}$ as indicated. dropped from $A$ to $R$. The broken portion of the proposed summary function is, to date, unsupported by empirical data; its shape was deduced from its known value where $A=65 \%$ and our contention that the factor which will differentiate ape/macaque Ss from squirrel monkey Ss, given that they are naive and introduced to fixed-trial DR training, is that their initial learning will be manifested in $R$ rather than $A$ performances, yielding $R / A>$ 1.00 for apes and macaques and $\mathrm{R} / \mathrm{A}<1.00$ for squirrel monkeys.

Our analysis of the $R / A$ ratio's functional relationship implies that primate taxa differ not only in capacity to (a) acquire discrimination learning sets and (b) acquire discrimination reversal sets for problems of a given class, but also with respect to the way in which these two kinds of sets develop and function one with another.

\section{References}

Harlow, H. F. The evolution of learning. In A. Roe \& G. G. Simpson (Eds.), Behavior and evolution. New Haven: Yale University Press, 1958. Pp. 269-290.

Harlow, H. F., \& Hicks, L. H. Discrimination learning theory: Uniprocess vs, duoprocess. Psychol. Rev., 1957, 64, 104-109.

Kendler, H. H., \& Kendler, T. S. Vertical and horizontal processes in problem-solving. In R. J. C. Harper, C. C. Anderson, C. M. Christensen, \& S. M. Hunka (Eds.), The cognitive processes. Englewood Cliffs: Prentice-Hall, 1964. Pp. 585-600.

Reese, H. W. Discrimination learning set in children. In L. P. Lipsitt \& C. C. Spiker (Eds.), Advances in child development and behavior. New York: Academic Press, 1963. Pp. 115-145.

Riopelle, A. J. Transfer suppression and learning sets. J. comp. physiol. Psychol., 1953, 46, 108-114.

Rumbaugh, D. M., \& Ensminger, L. W. Discrimination reversal training with single and multiple stimulus pairs in the squirrel monkey. J. comp. physiol. Psychol., 1964, 57, 304-306.

Rumbaugh, D. M., \& Rice, C. P. Learning-set formation in young great apes. J. comp. physiol. Psychol., 1962, 55, 866-868.

Rumbaugh, D. M., \& McCormack, C. P. The ontogeny of objectquality learning set in the lowland gorilla. Paper read at the Western Psychological Association, 1965.

Sperling. S. E. Reversal learning and resistance to extinction: A review of the rat literature. Psychol. Bull., 1965, 63, 281-297.

Warren, J. M., \& Kimball, H. Transfer relations in discrimination learning by cats. J. comp. physiol. Psychol., 1959, 52, 336-338.

Warren, J. M. Overtraining $x$ species $x$ task interaction. Paper read at the American Psychological Association, 1962.

\section{Notes}

1. Supported by NSF Grant 1942. Austin H. Riesen's contributions of interest and critical comment are gratefully acknowledged. 2. Subsequent to our formulations and writing of the present paper there has been published a closely related paper of considerable interest: Rajalakshimi, R., \& Jeeves, M. A. The relative difficulty of reversal learning (reversal index) as a basis of behavioural comparisons. Anim. Behav., 1965, 8, 203-211. 